\title{
Lesões crônicas da laringe pela intubação traqueal"
}

\author{
Marlos de SOUZA CoelHO ${ }^{1}$, Wilson de SOUZA StORI JunioR ${ }^{2}$
}

\begin{abstract}
Introdução: Várias complicações, muitas vezes graves, têm sido relacionadas com a intubação traqueal (IT), com incidência chegando a 18\%. Objetivos: Analisar as alterações da laringe provocadas pela IT: o desenvolvimento de estenose e de granuloma na laringe e a evolução da voz. Pacientes e métodos: Foram estudados prospectivamente 73 pacientes internados na Unidade de Terapia Intensiva do Hospital Cajuru, da Pontifícia Universidade Católica do Paraná, na região Sul do Brasil, submetidos a IT por cinco dias consecutivos e com previsão de necessidade de IT por mais sete dias, que foram traqueostomizados no sexto dia de IT. Foi realizada fibrolaringotraqueobroncoscopia (FLTB) nos $6^{\circ}, 14^{\circ}, 21^{\circ}, 28^{\circ}, 60^{\circ}, 90^{\circ}$ e no $180^{\circ}$ dias após a IT. Resultados: No $180^{\circ}$ dia do estudo havia 30 pacientes sobreviventes: 18 apresentavam voz normal, nove não puderam ser avaliados $e$ três apresentavam disfonia. Em oito pacientes foram observados granulomas na laringe, sendo que cinco foram curados espontaneamente, dois foram ressecados e um permaneceu no $180^{\circ}$ dia do estudo. Apenas um paciente apresentou estenose de laringe. Conclusões: Devido ao menor tempo de exposição da laringe ao trauma da cânula orotraqueal, a realização da traqueostomia no $6^{\circ}$ dia da IT parece causar poucas complicações. (J Pneumol 2001;27(2):68-76)
\end{abstract}

\section{Chronic larynx lesions by tracheal intubation}

Several complications, often very severe, have been associated with tracheal intubation (TI).

Incidence reaches up to $18 \%$. Objectives: To analyze larynx lesions caused by TI; the development of stenosis and granuloma in the larynx, and voice evolution. Patients and methods: This study analyzed prospectively 73 patients in the Intensive Care Unit of the Hospital Cajuru - Pontifical Catholic University of Paraná, southern Brazil. For five consecutive days, patients were submitted to TI, foreseen to be necessary for seven additional days. They were submitted to tracheostomy on the sixth day post-TI. Fibrolaryngotracheobronchoscopy was performed on the $6^{\text {th }}, 14^{\text {th }}, 21^{\text {st }}, 28^{\text {th }}, 60^{\text {th }}, 90^{\text {th }}$, and $180^{\text {th }}$ days post-intubation. Results: By the $180^{\text {th }}$ day, 30 patients had survived: $18(60 \%)$ patients showed normal voice; 9 (30\%) could not be evaluated; and $3(10 \%)$ presented dysphonia. Eight patients presented granulomas in the larynx - 5 of them were spontaneously cured, 2 (25.0\%) were resected, and 1 remained after the $180^{\text {th }}$ day. Stenosis in the larynx was detected in only 1 patient. Conclusions: Thanks to the shorter time of exposure of the larynx to the trauma caused by the orotracheal cannula, the performance of tracheostomy on the sixth day seems to cause few complications.

* Trabalho realizado no Hospital Universitário Cajuru PUC-PR.

1. Chefe do Serviço de Cirurgia Torácica e Endoscopia Respiratória; Mestre em Cirurgia.

2. Médico Assistente do Serviço de Cirurgia Torácica e Endoscopia Respiratória.

Endereço para correspondência - Av. Comendador Franco, 2.429 81520-000 - Curitiba, PR. Tel.: (41) 266-3500; Fax: (41) 266-4349; Site: www.marloscoelho.com.br; E-mail: clinicadotorax@marloscoelho. com.br

Recebido para publicação em 31/5/00. Reapresentado em 27/ 7/00. Aprovado, após revisão, em 24/10/00.
Descritores - Intubação intratraqueal. Traqueostomia. Estenose traqueal. Laringostenose. Granuloma laríngeo.

Key words - Intratracheal intubation. Tracheostomy. Tracheal stenosis. Laryngostenosis. Laryngeal granuloma.

\section{INTRODUÇÃO}

Várias complicações, muitas vezes graves, têm sido relacionadas a IT, com incidência global variando de $0 \%$ a $18 \%^{(1,2)}$. 
Os pacientes vítimas de politraumatismo, traumatismo craniencefálico, acidente vascular encefálico, intoxicação exógena aguda, em pós-operatório de cirurgia de grande porte e em outros estados que necessitem de IT, têm, muitas vezes, suas lesões agravadas pelo desenvolvimento de estenose da laringe, principalmente nas crianças.

A estenose da laringe, entidade complexa, exige cuidados que podem envolver endoscopias múltiplas, dilatações endoscópicas, ressecções endoscópicas, criocirurgia, ressecções a laser, traqueostomia, laringoplastia, molde intralaríngeo, enxerto de cartilagem e ressecções cricotraqueais, com o tratamento se estendendo por meses ou anos, necessitando, às vezes, até a traqueostomia definitiva ${ }^{(3-7)}$.

Lindholm ${ }^{(8)}$, em estudo prospectivo, encontrou índice de $63 \%$ de lesões agudas da laringe em pacientes submetidos a IT e que foram reversiveis em 30 dias. Observou $0,5 \%$ de estenose da laringe nos pacientes adultos e $6,7 \%$ nas crianças, sendo que $80 \%$ dos adultos e $33 \%$ das crianças permaneceram intubados por menos de 36 horas.

Stauffer et al..$^{(9)}$, em estudo prospectivo de 150 pacientes com intubação traqueal e traqueostomia, encontraram, em 95\%, lesões da laringe na autópsia e 7,4\% de estenose subglótica em longo prazo.

Kastanos et al. ${ }^{(10)}$ descreveram incidência de $42 \%$ de granulomas de laringe, porém nenhum caso de estenose da laringe.

Whited ${ }^{(11)}$ observou $2 \%$ de estenose da laringe em pacientes com IT entre três e cinco dias; $5 \%$ de estenose da laringe com IT entre seis e dez dias; e 14\% de estenose da laringe nos pacientes com IT acima de dez dias.

Grundfast et al. ${ }^{(12)}$ observaram $2 \%$ de estenose subglótica em 195 pacientes neonatos intubados acima de 48 horas.

Portanto, mesmo em centros considerados de excelência em cuidados intensivos, a ocorrência de estenose de laringe por IT varia de $0,5 \%^{(1)}$ a $14 \%^{(11)}$.

Essa discrepância de incidência de complicações laríngeas pela IT e o nosso contato diário com pacientes sob cuidados respiratórios intensivos com IT fizeram com que desde 1985 indicássemos a traqueostomia precoce no sexto dia de IT e motivaram o presente estudo.

Este trabalho tem por objetivo estudar o desenvolvimento da estenose da laringe, a evolução da voz e outras lesões crônicas da laringe nos pacientes intubados e submetidos a traqueostomia no $6^{\circ}$ dia nos pacientes admitidos na UTI Geral e na Unidade de Terapia Coronariana (UTC) do Hospital Universitário Cajuru da Pontifícia Universidade Católica do Paraná.

\section{CAsuística e MÉTODO}

Foram estudados, prospectivamente, 73 pacientes submetidos a IT da UTI Geral do Hospital Cajuru, da Pontifí-
Siglas e abreviaturas utilizadas neste trabalho

IT - Intubação traqueal

FLTB - Fibrolaringotraqueobroncoscopia

TRDL - Tempo de resolução do dano laríngeo

PVD - Prega vocal direita

PVE - Prega vocal esquerda

$\mathrm{CP}$ - Comissura posterior

HD - Hemilaringe direita

TIT - Tempo de intubação traqueal

UTI - Unidade de terapia intensiva

UTC - Unidade de terapia coronariana

PVC - Pressão venosa central

$\mathrm{NO}$ - Normal

$\mathrm{N}$ - Neurológico

$\mathrm{T}$ - Traqueostomia

cia Universidade Católica do Paraná, no período de $1^{\circ}$ de agosto de 1994 a 31 de julho de 1995.

Sessenta e três pacientes eram do sexo masculino $(86,3 \%)$ e dez do feminino $(13,7 \%)$, com idade variando de 16 a 92 anos, e idade média de 36 anos.

Cinqüenta pacientes $(68,5 \%)$ apresentaram traumatismo e 23 (31,5\%), doença não traumática.

Critérios de admissão no estudo: pacientes submetidos a IT por cinco dias consecutivos, com previsão de necessidade de intubação por mais de sete dias. Pacientes sem intubação traqueal no mesmo internamento; pacientes sem lesão prévia da laringe; pacientes sem traumatismo da laringe; pacientes que se submeteram a traqueostomia no sexto dia de IT.

Os pacientes foram intubados com cânula endotraqueal de PVC siliconizada, número 7,5 ou 8 para as mulheres e 8 ou 8,5 para os homens, utilizando a via oral.

As cânulas foram fixadas ao pescoço por meio de cadarço e nó ao redor do tubo, tomando como reparo os dentes incisivos superiores. As traqueostomias foram efetuadas no sexto dia de IT por cirurgiões do Serviço de Cirurgia Geral ou do Serviço de Cirurgia Torácica sob supervisão e padronização da técnica pelo autor. A traqueostomia foi efetuada de duas maneiras: a) incisão longitudinal do segundo e terceiro anéis traqueais (35 pacientes); ressecção de segmento da parede anterior do segundo ou terceiro anel traqueal (38 pacientes).

A via utilizada para FLTB foi nasal em 71 pacientes. Quando esta não era viável ou contra-indicada por condições anatômicas, hemorragia ou trauma craniofacial, utilizou-se a via oral com bocal protetor entre os dentes incisivos (dois pacientes).

As FLTB foram efetuadas sob anestesia tópica da narina, fossas nasais, faringe e porção glótica e supraglótica da laringe com xylocaína a $1 \%$ spray, e da laringe subglótica, traquéia e brônquios com xylocaína líquida a $1 \%$ por 
punção através da membrana cricotireóidea. Nos pacientes com cânula de traqueostomia, $5 \mathrm{ml}$ de xylocaína a $1 \%$ por via transcricóide e $5 \mathrm{ml}$ diretamente na cânula de traqueostomia, para anestesia subglótica e traqueal, respectivamente.

Em relação às lesões agudas e crônicas da laringe, adotou-se uma classificação baseada nas de Lindholm ${ }^{(8)}$, Whited $^{(11)}$ e Benjamin ${ }^{(13)}$ (Quadro 1).

Quarenta e três pacientes foram a óbito e, portanto, excluídos. Nos 30 pacientes sobreviventes estudou-se detalhadamente a evolução das lesões da laringe, a voz e a integridade das pregas vocais, a ocorrência de granuloma e de estenose de laringe.

A voz foi classificada em normal (NO); neurológico (N), quando pelo estado neurológico não se pudesse avaliar a fonação; traqueostomia $(\mathrm{T})$, quando a presença de traqueostomia impedia a avaliação adequada da voz; neurológico mais traqueostomia $(\mathrm{N}+\mathrm{T})$; disfonia leve (fonoastenia, disfonia subjetiva ou discreta alteração objetiva da voz); e disfonia (quando havia disfonia evidente).

\begin{tabular}{|l|}
\multicolumn{1}{c|}{ QUADRO 1 } \\
\hline Lesões crônicas da laringe pela IT \\
\hline - Lingüeta de granulação \\
- Granuloma de intubação \\
- - Códulo fibro de retenção cicatrizado \\
- Cicatriz em sulco \\
- Edema de laringe crônico \\
- Paralisia das pregas vocais \\
- Paresia das pregas vocais \\
- Estenose de laringe \\
- - adtenose glótica posterior posterior dos processos vocais \\
- interaritenóidea \\
- Estenose glótica anterior \\
Estenose subglótica \\
\hline
\end{tabular}

\section{Resultados}

Foram realizadas 415 FLTB nos 73 pacientes, sendo que para análise do trabalho foram consideradas as realizadas no $6^{\circ}, 14^{\circ}, 21^{\circ}, 28^{\circ}, 60^{\circ}, 90^{\circ}$ e $180^{\circ}$ dia, perfazendo um total de 304 FLTB (Tabela 1). Apresentamos os resultados obtidos nos 30 pacientes que estavam vivos no $180^{\circ}$ dia.

\section{1) Evolução da voz e das pregas vocais (Quadro 2)}

No $180^{\circ}$ dia pós-intubação, 18 (60\%) dos pacientes, apresentavam voz normal, independente da presença ou não de úlcera, não apresentando diferença estatisticamente significativa.

Três (10\%) pacientes apresentaram disfonia: dois pacientes com disfonia leve e um paciente com disfonia moderada.

O paciente 7 apresentou disfonia leve devido à "cicatriz em sulco" por diminuição da mobilidade das pregas vocais.

No paciente 28 , com úlcera típica na glote, 32 dias de traqueostomia, 21 dias de ventilação assistida e 60 dias para observação da resolução do dano laríngeo, a disfonia era devida à paresia da prega vocal direita.

No paciente 24 havia paralisia da hemilaringe direita causando disfonia moderada, com úlcera típica em ferradura na FLTB inicial, 23 dias de ventilação assistida e 24 dias de traqueostomia.

Em nove pacientes, não foi possivel avaliação da voz $e$ das pregas vocais: cinco $(16,7 \%)$ pelo estado neurogênico; três $(10 \%)$ pelo estado neurogênico mais a presença de traqueostomia; e um $(3,3 \%)$ devido à presença de molde laríngeo para complemento de laringoplastia (Quadro 2).

As pregas vocais eram normais em 21 (70\%) dos pacientes no $180^{\circ}$ dia: seis dentre sete pacientes dos que não apresentaram úlcera e 15 dentre 23 pacientes dos com úlcera ao exame inicial, com significância estatística $(p<0,05)$ em relação à ausência de úlcera.

TABELA 1

FLTB nos pacientes submetidos a IT seguida de traqueostomia

\begin{tabular}{|c|c|c|c|c|c|c|}
\hline \multirow[t]{2}{*}{ FLTB } & \multicolumn{2}{|c|}{$\begin{array}{c}\text { Óbito } \\
(n=43)\end{array}$} & \multicolumn{2}{|c|}{$\begin{array}{l}\text { Sobreviventes } \\
\quad(\mathbf{n}=\mathbf{3 0})\end{array}$} & \multicolumn{2}{|c|}{$\begin{array}{c}\text { Total } \\
(n=73)\end{array}$} \\
\hline & Número & Proporção & Número & Proporção & Número & Proporção \\
\hline Protocolo & 101 & 2,35 & 203 & 6,77 & 304 & 4,16 \\
\hline Broncoaspiração & 34 & 0,79 & 45 & 1,50 & 79 & 1,08 \\
\hline Diagnóstico & 4 & 0,09 & 25 & 0,83 & 29 & 0,40 \\
\hline Ressecção & - & - & 2 & 0,07 & 2 & 0,03 \\
\hline Dilatação & - & - & 1 & 0,03 & 1 & 0,01 \\
\hline Total & 139 & 3,23 & 276 & 9,20 & 415 & 5,68 \\
\hline
\end{tabular}

Nota: O cálculo da proporção foi efetuado pelo número total de pacientes em cada grupo. 


\begin{tabular}{|c|c|c|c|c|c|c|}
\hline \multicolumn{7}{|c|}{$\begin{array}{c}\text { QUADRO } 2 \\
\text { Avaliação da voz e das pregas vocais no } 180^{\circ} \text { dia pós intubação traqueal }\end{array}$} \\
\hline \multirow[t]{2}{*}{ Evolução } & \multicolumn{2}{|c|}{$\begin{array}{l}\text { Sem úlcera } \\
\quad(n=7)\end{array}$} & \multicolumn{2}{|c|}{$\begin{array}{l}\text { Com úlcera } \\
\quad(n=23)\end{array}$} & \multicolumn{2}{|c|}{$\begin{array}{c}\text { Total } \\
(\mathbf{n}=\mathbf{3 0})\end{array}$} \\
\hline & $\mathbf{N}^{o}$ & $\%$ & $\mathbf{N}^{\mathbf{o}}$ & $\%$ & $\mathbf{N}^{o}$ & $\%$ \\
\hline \multicolumn{7}{|l|}{ Voz } \\
\hline Normal & 5 & 71,4 & 13 & 56,5 & 18 & 60,0 \\
\hline Disfonia & - & - & 3 & 13,1 & 3 & 10,0 \\
\hline Molde & - & - & 1 & 4,3 & 1 & 3,3 \\
\hline Neurológico & 2 & 28,6 & 3 & 13,1 & 5 & 16,7 \\
\hline Neurológico + traqueostomia & - & - & 3 & 13,0 & 3 & 10,0 \\
\hline \multicolumn{7}{|l|}{ Pregas vocais } \\
\hline Normal & 6 & 85,7 & 15 & 65,2 & 21 & 70,0 \\
\hline Cicatriz em sulco & - & - & 1 & 4,4 & 1 & 3,4 \\
\hline Molde & - & - & 1 & 4,4 & 1 & 3,3 \\
\hline Neurológico & 1 & 14,3 & 1 & 4,3 & 2 & 6,7 \\
\hline Neurológico + traqueostomia & - & - & 3 & 13,1 & 3 & 10,0 \\
\hline Paralisia da PVD + HD & - & - & 1 & 4,3 & 1 & 3,3 \\
\hline Paresia da PVD & - & - & 1 & 4,3 & 1 & 3,3 \\
\hline
\end{tabular}

\section{2) Granuloma da laringe}

Foram observados oito $(26,7 \%)$ casos de granulomas da laringe pós-IT, sendo um $(3,4 \%)$ na região subglótica; três $(10 \%)$ na comissura posterior; e quatro $(13,3 \%)$ nas pregas vocais: um $(3,3 \%)$ na prega vocal direita, dois $(6,6 \%)$ na prega vocal esquerda e um $(3,3 \%)$ com granuloma nas duas pregas vocais. Todos os pacientes eram do sexo masculino. A dimensão dos granulomas variou entre 2 e $8 \mathrm{~mm}$ (Quadro 3).

Todos os pacientes nos quais foram detectados granulomas de laringe apresentavam úlcera da laringe no exame inicial.

Cinco $(62,5 \%)$ granulomas foram observados no $28^{\circ}$ dia; um (12,5\%) no $14^{\circ}$ dia; um (12,5\%) no $21^{\circ}$ dia; e um $(12,5 \%)$ no $90^{\circ}$ dia (Quadro 3).

Cinco $(62,5 \%)$ pacientes tiveram evolução do granuloma para cura espontânea. Um paciente foi tratado com ressecção endoscópica, porque o granuloma progrediu de 4 para $8 \mathrm{~mm}$ entre o $28^{\circ}$ e $60^{\circ}$ dia, impedindo a retirada da cânula de traqueostomia. Após a ressecção endoscópica, o paciente teve a cânula de traqueostomia retirada e evoluiu para a cura.

Um paciente apresentou granuloma da comissura posterior, que, ao ser ressecado, permitiu análise completa da integridade das estruturas da laringe, evidenciando fixação posterior das pregas vocais, porém com permeabilidade glótica satisfatória. Evoluiu para estenose glótica posterior e subglótica, tratada com laringoplastia. Um

\begin{tabular}{|c|c|c|c|c|}
\hline \multicolumn{5}{|c|}{$\begin{array}{c}\text { QUADRO } 3 \\
\text { Granuloma da laringe pós-intubação traqueal } \\
\text { seguida de traqueostomia no } 6^{\circ} \text { dia }\end{array}$} \\
\hline Paciente & $\begin{array}{l}\text { Local do } \\
\text { granuloma }\end{array}$ & $\begin{array}{c}\text { Dia da } 1^{\mathrm{a}} \\
\text { observação }\end{array}$ & $\begin{array}{l}\text { Dia da } \\
\text { resolução }\end{array}$ & Dimensão \\
\hline 1 & $\mathrm{CP}$ & $21^{\circ}$ & $60^{\circ}$ & $2 \mathrm{~mm}$ \\
\hline 5 & $\mathrm{CP}$ & $28^{\circ}$ & $28^{\circ}$ & $4 \mathrm{~mm}$ \\
\hline 7 & PVE & $28^{\circ}$ & $90^{\circ}$ & $2 \mathrm{~mm}$ \\
\hline 9 & $\mathrm{CP}$ & $90^{\circ}$ & Permanece & $2 \mathrm{~mm}$ \\
\hline 10 & PVD + PVE & $14^{\circ}$ & $60^{\circ}$ & $2 \mathrm{~mm}$ \\
\hline 12 & PVD & $28^{\circ}$ & $180^{\circ}$ & $3 \mathrm{~mm}$ \\
\hline 13 & PVE & $28^{\circ}$ & $90^{\circ}$ & $2 \mathrm{~mm}$ \\
\hline 14 & Subglote & $28^{\circ}$ & $79^{\circ}$ & $4-8 \mathrm{~mm}$ \\
\hline $\begin{array}{r}\text { Nota: Paci } \\
\text { Paci } \\
\text { PVD - preg }\end{array}$ & $\begin{array}{l}\text { 4- Ressecçao } \\
\text { al direita; PVE - }\end{array}$ & prega vocal esque & dia. & $\begin{array}{l}\text { undo tempo. } \\
\text { posterior }\end{array}$ \\
\hline
\end{tabular}

$(12,5 \%)$ paciente permaneceu com granuloma assintomático após o $180^{\circ}$ dia.

\section{3) Estenose da laringe}

Ocorreu uma $(3,3 \%)$ estenose da laringe pós-IT seguida de traqueostomia no $6^{\circ}$ dia. Tratava-se de estenose glótica posterior e estenose subglótica da laringe associada a granuloma na comissura posterior, o qual foi ressecado. Posteriormente o paciente foi submetido a laringoplastia anterior e posterior, molde translaríngeo de silico- 


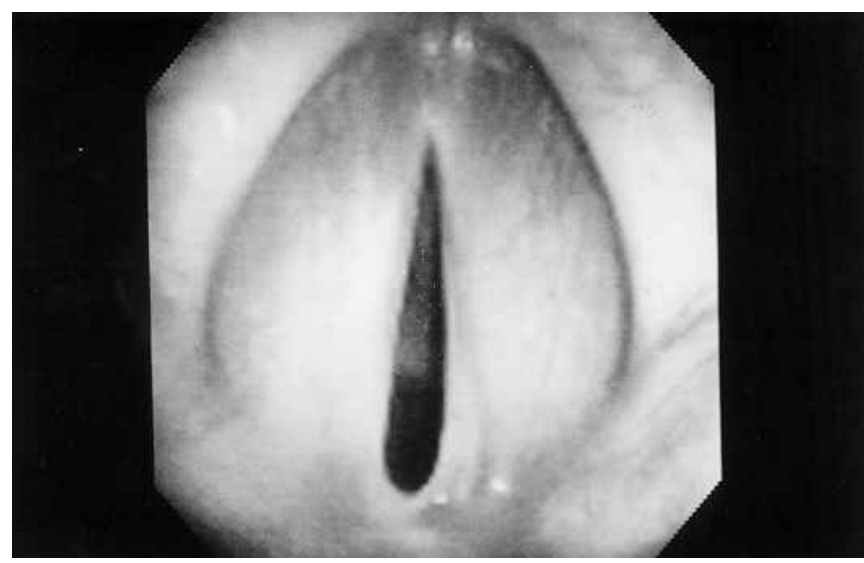

Fig. $1 A$

ne e enxerto anterior de cartilagem, técnica padronizada no serviço de Cirurgia Torácica do Hospital Cajuru (Figura $1, \mathrm{~A}$ e $\mathrm{B})$.

\section{Complicações}

São relatadas as complicações dos 73 pacientes iniciais.

Complicações da intubação traqueal: quatro casos $(5,5 \%)$ de intubação seletiva; um $(1,3 \%)$ de pneumotórax por barotrauma; dois $(2,7 \%)$ de descanulação acidental; dois $(2,7 \%)$ de dificuldade ou impossibilidade de oclusão da via aérea pelo balonete; um $(1,3 \%)$ de necrose do $2^{\circ}$ ao $6^{\circ}$ anel traqueal evidenciada por ocasião da traqueostomia com conseqüente óbito.

Complicações da traqueostomia: três doentes $(4,1 \%)$ de erosão do estoma; quatro $(5,5 \%)$ de infecção do estoma; um (1,3\%) de enfisema subcutâneo; um $(1,3 \%)$ de hemorragia discreta proveniente de vasos cervicais; dois $(2,7 \%)$ de lateralização do estoma por posição viciosa do pescoço e cabeça; três $(4,1 \%)$ de descanulações acidentais, sem maiores conseqüências, sendo duas vezes no mesmo paciente, que era psicopata; um $(1,1 \%)$ de estenose da traquéia entre a cricóide e o estoma, atribuída à

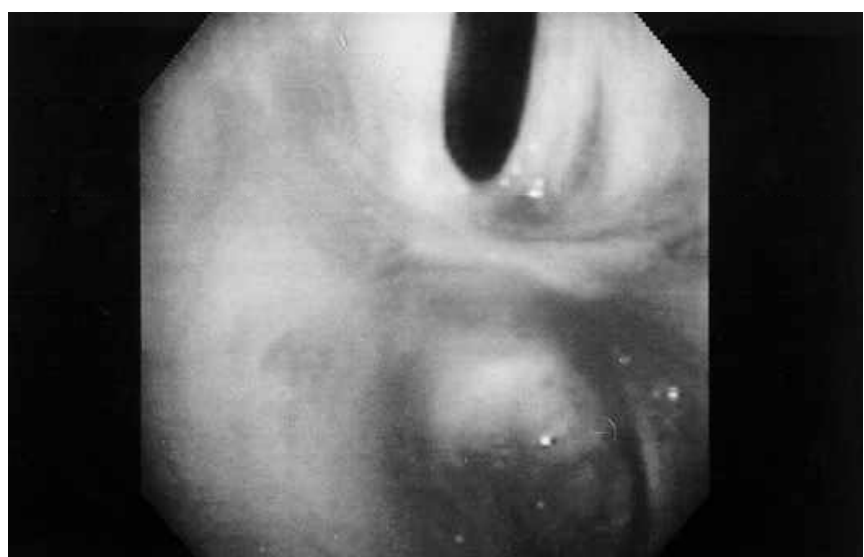

Fig. $1 B$

compressão da parede anterior da traquéia pela cânula de traqueostomia.

Complicações da intubação traqueal e/ou traqueostomia: dois $(2,7 \%)$ pacientes tiveram estenose da traquéia na união do terço médio com o inferior, que pode ser atribuída à compressão determinada pelo balonete do tubo endotraqueal ou da cânula de traqueostomia.

\section{DIsCUSSÃO}

\section{Evolução das alterações da voz e das lesões das pregas vocais após a IT seguida de traqueostomia}

A disfonia pode ser temporária e observada logo após a descanulação. Kastanos et al. ${ }^{(10)}$ relataram $63 \%$ de disfonia, incluído um doente cuja disfonia permaneceu por um ano sem lesão identificável na laringoscopia. Santos et al. (14) encontraram disfonia em $80 \%$ dos pacientes, sendo que $20 \%$ permaneceram disfônicos por oito semanas.

A maioria das lesões é ocasionada pela lesão direta sobre as pregas vocais, ocasionando edema ou ulcerações ou por alteração da mobilidade da articulação cricoaritenóidea e pelo efeito de molde ocasionado pela cânula translaríngea. Tais efeitos desaparecem, na maioria das vezes, com a regressão do processo inflamatório(15).

TABELA 2

Avaliação da voz no $180^{\circ}$ dia nos pacientes do grupo II, em relação à classe inicial

\begin{tabular}{|c|c|c|c|c|c|c|}
\hline \multirow[t]{2}{*}{ Avaliação da voz } & \multicolumn{2}{|c|}{ Leve } & \multicolumn{2}{|c|}{ Moderada } & \multicolumn{2}{|c|}{ Grave } \\
\hline & $\mathbf{N}^{\mathbf{o}}$ & $\%$ & $\mathbf{N}^{\mathbf{o}}$ & $\%$ & $\mathbf{N}^{\mathbf{o}}$ & $\%$ \\
\hline Normal & 7 & 70,0 & 11 & 57,9 & - & - \\
\hline Disfonia & 1 & 10,0 & 2 & 10,5 & - & - \\
\hline Molde & - & - & 1 & 5,3 & - & - \\
\hline Neurogênico & 2 & 20,0 & 3 & 15,8 & - & - \\
\hline Neurogênico + traqueostomia & - & - & 2 & 10,5 & 1 & 100,0 \\
\hline Total & 10 & 100,0 & 19 & 100,0 & 1 & 100,0 \\
\hline
\end{tabular}


Disfonia e broncoaspiração pós-descanulação resultam, habitualmente, da limitação da adução das pregas vocais. Quando existe recuperação da mobilidade da articulação cricoaritenóidea e o efeito de molde pela cânula regride, há o retorno da voz e do controle da broncoaspiração ao normal.

A paralisia ou fixação das pregas vocais é freqüentemente unilateral, mas pode ser bilateral. Pode apresentar-se como estridor e insuficiência respiratória até seis horas após a descanulação. Em alguns doentes há necessidade de traqueostomia na fase aguda, pois a resolução pode demorar semanas, meses ou ser irreversível. Nesta situação podem ser necessárias medidas de lateralização da prega vocal quando a paralisia é em adução ou injeção de teflon para posicionar a prega vocal em posição medial se a mesma está em abdução(1).

Quando as pregas vocais estão paralisadas em adução, ocorre obstrução da via aérea, a alteração da voz é discreta e a aspiração broncopulmonar é limitada. Quando a paralisia é em abdução, não há obstrução da via aérea, a voz é precária e a aspiração traqueobrônquica de saliva e alimentos não só é possivel como é freqüente.

A incidência varia de $1 \%{ }^{(22)}$ a $37 \%^{(10)}$. Esta discrepância existe porque alguns classificam como paralisia a paresia pós-IT.

Alguns autores admitem como causa: a compressão do nervo laríngico recorrente ao nível da cricóide posterior pelo balonete; processo inflamatório; lesão neurogênica ou mesmo indeterminada.

Paresia das pregas vocais é a diminuição em grau variado da mobilidade das pregas vocais, isoladamente ou não, ocasionada pelo trauma direto da cânula endotraqueal, alterações mucosas ou musculares ou alteração da mobilidade da articulação cricoaritenóidea. A paresia pósintubação é, na maioria das vezes, transitória, retornando as pregas vocais ao normal após a regressão das alterações inflamatórias ${ }^{(13)}$.

A incidência da disfonia crônica é variável: Stauffer et al. ${ }^{(9)}$ descreveram 7\%; Citta-Pietrolungo et al. ${ }^{(16)}, 23 \%$.

Dezoito (60\%) dos pacientes deste trabalho apresentaram voz normal no $180^{\circ}$ dia. Os pacientes com ausência de úlcera na FLTB inicial apresentaram índice maior de voz normal do que aqueles com úlcera $(p<0,05)$; portanto, a presença de úlcera no exame inicial implica maior incidência de disfonia. Nove não puderam ser avaliados pela presença de molde, estado neurogênico ou presença de traqueostomia ou ambos.

As pregas vocais estavam integras no $180^{\circ}$ dia em 21 (70\%) dos pacientes, tendo significância estatística em relação à ausência de úlcera $(\mathrm{p}<0,05)$.

A discordância entre voz normal $(60 \%)$ e integridade das pregas vocais $(70 \%)$ explica-se pelo fato de três pacientes neurogênicos permitirem a avaliação da integri- dade anatômica e da movimentação das pregas vocais com os movimentos respiratórios e a resposta ao comando de forma satisfatória.

Colice ${ }^{(17)}$ não encontrou relação entre a gravidade da lesão laríngea e a disfonia crônica.

As alterações motoras das pregas vocais, a paralisia e a paresia são ocasionadas, segundo Brandstein et al.(18), pela compressão do ramo anterior do nervo laríngico recorrente quando este passa entre a cartilagem aritenóide e a lâmina tireóide. Tal compressão seria pelo balonete situado a este nivel, por hiperinsuflação do balonete ou por tração do balonete insuflado sobre a região subglótica.

Peppard e Dickens ${ }^{(19)}$ encontraram dois $(0,4 \%)$ pacientes com disfonia devida à paralisia de prega vocal, secundária à IT por curto período, quando foram submetidos a anestesia geral.

Cohen ${ }^{(20)}$ relata seis casos inicialmente referidos como paralisia bilateral das pregas vocais e que a laringoscopia mostrou tratar-se de fixação posterior destas ou estenose glótica posterior (pseudoparalisia de laringe).

Astrachan et al. ${ }^{(21)}$ descreveram $1 \%$ de paralisa bilateral das pregas vocais em paciente com insuficiência respiratória que necessitou traqueostomia. Thomas et al. ${ }^{(22)}$ encontraram quatro $(3,7 \%)$ casos de paralisia das pregas vocais, sendo três de paralisia unilateral e um de paralisia bilateral.

Lindholm $^{(8)}$ relata disfonia leve em 15 (5,6\%) de 265 pacientes, sendo que em nove $(2,4 \%)$ a disfonia era devida à lesão do nervo laríngico recorrente por cirurgia intratorácica e, em um $(0,3 \%)$, já havia disfonia ao tempo da intubação. Em seis (2,2\%), foi devida à paresia de prega vocal relacionada à IT.

Aass $^{(23)}$ encontrou disfonia em seis $(13,9 \%)$ de 43 pacientes, sendo que quatro $(9,3 \%)$ apresentavam laringe normal à laringoscopia e dois $(4,6 \%)$, paralisia da prega vocal esquerda.

\section{Granuloma da laringe}

A cicatrização da laringe que se realiza por segunda intenção é complexa e influenciada por constante movimento de estreitamento e expansão desta, ocorrido durante a respiração, fonação e deglutição. A reparação das úlceras do epitélio inicia-se na membrana basal quando está intacta. Entretanto, se esta foi destruída, o processo de cicatrização é lento, iniciando a partir das bordas do tecido ulcerado. Movimentos contínuos, com desorganização desse processo, produzem o granuloma ${ }^{(25)}$.

Alguns fatores são sugeridos como predisponentes para a formação de granuloma: a idade adulta, sexo feminino, estetoscópios esofágicos, anemia, hipotensão, desnutrição, infecção respiratória, diabete melito e outros semelhantes aos fatores predisponentes e/ou desencadeantes de modo geral ${ }^{(14,24)}$. Nesta série, não encontramos rela- 
ção entre esses fatores e o desenvolvimento de granuloma da laringe.

Tipicamente de cor marrom amarelada, pediculados, situados na prega vocal ou porção medial da cartilagem aritenóide, podem estar presentes em outras regiões da laringe e na traquéia em áreas de contato com o tubo ou nas bordas da traqueostomia(25). Regridem após a descanulação e, em algumas ocasiões, exigem ressecção endoscópica.

Lindholm ${ }^{(8)}$ encontrou granuloma de laringe em 26 (38\%) de 65 pacientes. O seu aparecimento ocorreu em média em 21 dias. Em 24 (92,3\%) destes, houve regressão espontânea num período de três meses; em dois $(7,6 \%)$ pacientes houve necessidade de ressecção endoscópica.

Stauffer et al. ${ }^{\left({ }^{9}\right)}$ encontraram um caso $(2,2 \%)$ de granuloma em 44 dos seus pacientes sobreviventes submetidos à IT e IT seguida de traqueostomia, porém só realizavam endoscopia nos pacientes com sintomas obstrutivos.

Kastanos et al. ${ }^{(10)}$ observaram oito (42\%) pacientes com granuloma da laringe em 19 pacientes submetidos a IT e examinados endoscopicamente no $10^{\circ}$ dia pós-descanulação, sendo que dois necessitaram ressecção endoscópica. Entre nós, Porto e Alves ${ }^{(25)}$ encontraram oito $(1,2 \%)$ de granuloma da laringe em 662 microcirurgias de laringe, referindo ser quatro na prega vocal esquerda e um na epiglote, que também é submetida a contato com a cânula endotraqueal e sua movimentação. Colice et al. ${ }^{(1)}$ encontraram granuloma de laringe em seis $(7 \%)$ de 86 pacientes, sendo que três (10\%) necessitaram tratamento endoscópico.

Em série de 150 pacientes de UTI submetidos somente a IT, Thomas et al. ${ }^{(22)}$ não encontraram granuloma de la- ringe, porém fizeram a FLTB por dentro da cânula na ocasião da descanulação, o que não permite visualização adequada, bem como a época ser precoce para o aparecimento do granuloma. Posteriormente, realizavam a FLTB apenas nos pacientes sintomáticos.

Nesta série, a presença de granuloma da laringe foi detectada em oito $(26,7 \%)$ de 30 pacientes do grupo II com seguimento de seis meses. A maioria, cinco $(62,5 \%)$, foi observada no $28^{\circ}$ dia, o que permite concluir que o seu aparecimento ocorreu entre o $21^{\circ}$ e o $28^{\circ}$ dia, ocasiões da $3^{\mathrm{a}}$ e $4^{\mathrm{a}}$ FLTB do protocolo. Todos os pacientes apresentaram úlcera de laringe que precedeu o granuloma da laringe. O desaparecimento do granuloma ocorreu entre o $60^{\circ}$ e $90^{\circ}$ dia em cinco pacientes. Dois (25\%) pacientes necessitaram ressecção endoscópica. Um $(12,5 \%)$ paciente com granuloma da comissura posterior permaneceu assintomático após o $180^{\circ}$ dia.

\section{Estenose da laringe}

Lindholm ${ }^{(8)}$ relatou a presença de estenose da laringe em um $(0,37 \%)$ de 267 pacientes adultos e em três $(6,6 \%)$ de 45 pacientes pediátricos, sendo duas $(4,4 \%)$ estenoses subglóticas e uma $(2,25 \%)$ estenose glótica posterior (anel fibroso), a qual foi tratada por dilatação (Quadro 4).

El-Naggar et al. ${ }^{(26)}$ publicaram a presença de estenose da laringe em dois $(3,8 \%)$ de 52 pacientes; Kastanos et al. ${ }^{(10)}, 0 \%$ em 19 pacientes; Colice et al. ${ }^{(1)} 0 \%$ em 86 pacientes; Thomas et al. ${ }^{(22)}$, cinco $(3,3 \%)$ em 150 pacientes. Whited ${ }^{(27)}$ publicou $12(6 \%)$ casos de estenose da laringe em 200 pacientes de estudo prospectivo, sendo que, para pacientes com IT até cinco dias, a incidência de estenose da laringe foi de $2 \%$; nos com IT entre cinco e

\begin{tabular}{|c|c|c|c|c|c|c|}
\hline \multicolumn{7}{|c|}{$\begin{array}{c}\text { QUADRO } 4 \\
\text { Incidência da estenose da laringe pela IT }\end{array}$} \\
\hline Autor & Ano & $N^{0}$ de pacientes & Estenose & $\%$ & Idade & TIT \\
\hline \multirow[t]{2}{*}{ Lindholm } & 1969 & 45 & 3 & 6,6 & Ped. & Variável \\
\hline & & 267 & 1 & 0,3 & Adulto & Variável \\
\hline El Naggar et al. & 1976 & 52 & 2 & 3,8 & Adulto & $\uparrow 3$ dias \\
\hline Stauffer et al. & 1981 & 27 & 2 & 7,4 & Adulto & $\uparrow 6$ dias \\
\hline Kastanos et al. & 1983 & 19 & 0 & 0 & Adulto & $\uparrow 1 \mathrm{dia}$ \\
\hline \multirow[t]{3}{*}{ Whited } & 1984 & 50 & 1 & 2 & Adulto & 3-5 dias \\
\hline & & 100 & 5 & 5 & Adulto & 6-10 dias \\
\hline & & 50 & 7 & 14 & Adulto & $10-24$ dias \\
\hline Colice et al. & 1989 & 86 & 0 & 0 & Adulto & $\uparrow 5$ dias \\
\hline Woo & 1989 & 50 & 9 & 18 & $10-80 \mathrm{~A}$. & Indet. \\
\hline Grundfast & 1990 & 195 & 4 & 2,1 & Neon & $\uparrow 2$ dias \\
\hline Thomas et al. & 1995 & 150 & 5 & 3,3 & Var. & $\uparrow 1$ dia \\
\hline Coelho & 1996 & 30 & 1 & 3,3 & Adulto & 6 dias \\
\hline
\end{tabular}


dez dias, foi de 5\%; e nos pacientes com IT acima de dez dias, a incidência foi de $14 \%$.

Woo et al. ${ }^{(2)}$, em 50 pacientes com traumatismo craniencefálico grave e disabilidade intensa de acordo com a Escala de Alta, encontraram elevados índices de estenose da laringe: nove (18\%), sendo três (6\%) de estenose subglótica, três $(6 \%)$ de estenose glótica, um $(2 \%)$ de estenose supraglótica e dois (4\%) com anquilose da articulação cricoaritenóidea. Não forneceram detalhes sobre o tempo de IT, uma vez que os pacientes já chegaram ao seu serviço com traqueostomia. Nessa série houve um caso $(3,3 \%)$ de estenose de laringe em um paciente com estenose glótica posterior associada à estenose subglótica $e$ granuloma da comissura posterior.

Grundfast et al.(12) encontraram, dentre 199 neonatos intubados por mais de 48 horas, quatro $(2,1 \%)$ casos de estenose subglótica.

Múltiplos fatores influenciam na diferença de incidência: tempo de IT; dificuldade técnica na realização dos exames endoscópicos; exames endoscópicos deficientes; dificuldade de controle dos fatores desencadeantes e/ou agravantes; dificuldade no seguimento dos pacientes; $e$, principalmente, a definição apropriada da estenose da laringe e a classificação adequada das estenoses laringotraqueais.

Harley ${ }^{(28)}$ definiu com propriedade a estenose subglótica, denominando-a estenose infraglótica ou cricóidea; portanto, sendo realmente estenose da laringe e não da traquéia. A extensão da estenose subglótica para o primeiro e o segundo anéis traqueais foi denominada estenose laringotraqueal. Stauffer et al. ${ }^{(9)}$, em estudo amplamente citado na literatura, descreveram que, nos seus 27 pacientes sobreviventes submetidos somente a IT, ocorreram cinco estenoses de traquéia, sendo três ao nível do balonete e duas ao nivel da região subglótica. Portanto, Stauffer et al., defensores da IT além de 14 dias, não computaram como estenose de laringe os dois $(7,4 \%)$ de estenose subglótica.

Cohen ${ }^{(20)}$ publicou sete casos de estenose glótica posterior em pacientes pediátricos que foram enviados a seu serviço com diagnóstico de paralisia bilateral das pregas vocais.

A estenose glótica anterior é de ocorrência rara, ocasionada por ponte de tecido fibroso entre as pregas vocais na sua porção anterior em área de ulceração pré$\mathrm{via}^{(29)}$.

Isquemia causada por pressão exercida pela cânula sobre a laringe, seguida de infecção na glote posterior, resulta em cicatriz de vários graus em três áreas principais: face medial das cartilagens aritenóides, área interaritenóidea ou comissura posterior e processos vocais.

A mucosa que cobre as aritenóides e áreas interaritenóideas está sobre fina camada de submucosa e fino mu- copericôndrio. Com a pressão e isquemia, forma-se úlcera com exposição da cartilagem e possivel pericondrite com fibrose da área ulcerada e infectada. O músculo interaritenóideo e área interaritenóidea tornam-se fibrosados $e$ fixos. A ulceração e fibrose da área do processo vocal resultam em fusão da porção posterior da prega vocal verdadeira e a extensão desta cicatriz atinge a comissura posterior ${ }^{(21)}$.

Se há fixação parcial ou total das articulações cricoaritenóideas com aproximação das pregas vocais, pode haver graus variados de obstrução respiratória com alteração discreta da voz, sendo comum o diagnóstico equivocado de paralisia de prega vocal.

O tecido de granulação pode cruzar a linha média, ocasionando a estenose glótica posterior, ou a superfície ulcerada das pregas vocais se adere na linha média. Freqüentemente, ao nivel dos processos vocais, portanto posteriormente, formando banda que limita a abdução das pregas vocais. Essa adesão das pregas vocais pode ocorrer na sua porção média, formando orifício posterior $e$ fenda triangular anterior, que pode ser seccionada por microcirurgia ou laser.

Whited ${ }^{(27)}$ admite dois tipos de estenose glótica posterior: a) pela adesão posterior dos processos vocais na área de ulceração prévia e pelo plano interaritenóideo através de cicatrização de úlcera glótica posterior, mais especificamente a úlcera em ferradura.

O diagnóstico é difícil, muitas vezes exigindo anestesia geral para a laringoscopia direta, que evidenciará limitação da movimentação das pregas vocais. A comissura posterior das pregas vocais deve ser testada com afastador para demonstrar sua fixação. Caso o diagnóstico correto da estenose glótica posterior ou da sua associação com estenose subglótica não seja feito, a falha do tratamento será inevitável.

A estenose subglótica é mais comum nas crianças em virtude de ser a cricóide a porção mais estreita da via aérea e devido ao anel cartilaginoso rígido permitir que o edema e o espessamento somente se manifestem para o interior da luz ${ }^{(8)}$.

A traquéia cervical quase sempre é envolvida (83\%) e pode haver associação com a estenose glótica $(25 \%)^{(31)}$.

Pode-se subdividir a estenose subglótica em: a) estenose subglótica mole; e b) estenose subglótica fibrótica. A estenose subglótica fibrótica pode ocorrer pós-cricotireoidostomia ${ }^{(32,33)}$ e após "traqueostomia alta", comprometendo o primeiro anel traqueal. Quando há destruição da cartilagem traqueal, esta pode atingir a cartilagem cricói$\mathrm{d} e^{(29)}$, podendo também ocorrer pós-intubação traqueal.

Sasaki e Horiuchi ${ }^{(30)}$, em estudo em cães, demonstraram que a contaminação bacteriana da laringe lesada proveniente da traqueostomia leva ao desenvolvimento de estenose da laringe. $\mathrm{O}$ pequeno número de estenose 
da laringe desta série não permite chegar a esta conclusão.

Kirschner e Sasaki(31) afirmam que a conversão da IT para traqueostomia propiciaria o aparecimento de estenose glótica posterior, isto porque a traqueostomia leva ao repouso das pregas vocais, permitindo que áreas desnudas da comissura posterior e pregas vocais entrem em contato e cicatrizem com fibrose, provocando a aderência entre as pregas vocais. Lieberman et al. ${ }^{(34)}$ não confirmaram, em estudo experimental em cães, a ocorrência da paralisia do músculo cricoaritenóideo; portanto, a paralisia das pregas vocais após a traqueostomia não favorece a fixação das pregas vocais.

Concluímos que a realização da traqueostomia no sexto dia de intubação traqueal, em virtude do menor tempo de exposição da laringe ao trauma da cânula orotraqueal, foi responsável pelos índices de disfonia (10\%), lesões das pregas vocais $(10 \%)$, granuloma da laringe $(26,6 \%)$ e de estenose da laringe $(3,3 \%)$ encontrados neste trabalho.

\section{REFERÊNCIAS}

1. Colice GL, Stukel TA, Dain B. Laryngeal complications of prolonged intubation. Chest 1989;96:877-883.

2. Woo P, Kelly G, Kirshner P. Airway complications in the head injured. Laryngoscope 1989;99:725-731.

3. Cotton RT, Evans JNJ. Laryngotracheal reconstruction in children. Ann Otol Rhinol Laryngol 1981;90:516-520.

4. Prescott CAJ. Protocol for management of the interposition cartilage graft laryngotracheoplasty. Ann Otol Rhinol Laryngol 1988;97:239242.

5. Seid AB, Pransky SM, Kearns DB. One-stage laryngotracheoplasty. Arch Otolaryngol Head Neck Surg 1991;117:408-410.

6. Ranne RD, Lindley S, Holder TM, et al. Relief of subglottic stenosis by anterior cricoid resection: an operation for the difficult case. J Pediatr Surg 1991;26:255-259.

7. Anand VK, Alemar G, Warren ET. Surgical considerations in tracheal stenosis. Laryngoscope 1992;102:237-243.

8. Lindholm CE. Prolonged endotracheal intubation. A clinical investigation with special reference to its consequences for the larynx and trachea and to its place an alternative to intubation through a tracheostomy. Acta Anaesthesiol Scand 1969;33:1-131.

9. Stauffer JL, Olson DE, Petty TL. Complications and consequences of endotracheal intubation and tracheostomy: a prospective study of 150 critically ill adult patients. Am J Med 1981;70:65-75.

10. Kastanos N, Miró RE, Perez AM, et al. Laryngotracheal injury due to endotracheal intubation: incidence, evolution, and predisponig factors. A prospective long-term study. Crit Care Med 1983;11:362-367.

11. Whited RE. A prospective study of laryngotracheal sequelae in longterm intubation. Laryngoscope 1984;94:367-377.

12. Grundfast KM, Camilon FS, Barber CS, et al. Prospective study of subglottic stenosis in intubated neonates. Ann Otol Rhinol Laryngol 1990;99:390-395.
13. Benjamin B. Prolonged intubations injuries of the larynx: endoscopic diagnosis, classification, and treatment. Ann Otol Rhinol Laringol 1993; 102(Suppl 160):1-15.

14. Santos P, Afrassiabi A, Weymuller E. Prospective studies evaluating the standard endotracheal tube and a prototype endotracheal tube. Ann Otol Rhinol Laringol 1989;98:935-940.

15. Weymuller EA, Bishop M. Problems associated with prolonged intubations in the geriatric patient. Otolaryngol Clin North Am 1990;23:5773.

16. Citta-Pietrolungo TJ, Alexander MA, Cook SP, et al. Complications of tracheostomy and decanulation in pediatric and young patients with traumatic brain injury. Arch Phys Med Rehabil 1993;74:905-909.

17. Colice GL. Resolution of laryngeal injury following translaryngeal intubation. Am Rev Respir Dis 1992;145:361-364.

18. Brandstein M, Abramson AL, Shikowitz MJ. Bilateral vocal cord paralysis following endotracheal intubation. Arch Otolaryngol Head Neck Surg 1986;112:877-882.

19. Peppard SB, Dickens JH. Laryngeal injury following short-term intubation. Ann Otol Rhinol Laryngol 1983;92:327-330.

20. Cohen SR. Pseudolaryngeal paralysis: a post intubation complication. Ann Otol Rhinol Laryngol 1981;90:483-488.

21. Astrachan DI, Kirchner JC, Goodwin Jr WJ. Prolonged intubation vs. tracheostomy: complications, practical and psychological considerations. Laryngoscope 1988;98:1165-1169.

22. Thomas R, Kumar EV, Kameswaran M, et al. Post intubation sequelae in an intensive care unit. J Laryngol Otol 1995;109:313-316.

23. Aass AS. Complications to tracheostomy and long-term intubation: a follow-up study. Acta Anaesthesiol Scand 1975;19:127-133.

24. Balestrieri F, Watson CB. Intubation granuloma. Otolaryngol Clin North Am 1982;15:567-579.

25. Porto AJS, Alves SN. Granuloma pós-entubação. Rev Bras Anestesiol 1989;39:43-45.

26. El-Naggar M, Sadagopan S, Levine $\mathrm{H}$, et al. Factors influencing choice between tracheostomy and prolonged translaryngeal intubation in acute respiratory failure: a prospective study. Anesth Analg 1976;55:195201.

27. Whited RE. Posterior commissure stenosis post long-term intubation. Laryngoscope 1983;93:1314-1318.

28. Harley HRS. Laryngotracheal obstruction complicating tracheostomy or endotracheal intubation with assisted respiration. Thorax 1971;26: 493-533.

29. Strome M, Ferguson CF. Multiple postintubation complications. Ann Otol Rhinol Laryngol 1974;83:432-438.

30. Sasaki CT, Horiuchi M, Koss N. Tracheostomy related subglottic stenosis. Bacteriologic pathogenesis. Laryngoscope 1979;89:857-865.

31. Kirchner JA, Sasaki CT. Fusion of the vocal cords following intubation and tracheostomy. Trans Am Acad Ophthalmol Otolaryngol 1981;77: 88-91.

32. Jackson J. High tracheostomy and other errors the chief causes of chronic laryngeal stenosis. Surg Gynecol Obstet 1932;32:392-398.

33. Brantigan LO, Grow JB. Cricothyroidotomia: elective use in respiratory problems requiring tracheotomy. J Thorac Cardiovasc Surg 1976;71: 71-81.

34. Lieberman MR, Malgreen LT, Woo P. The effect of tracheotomy on posterior cricoarytenoid muscle. Laryngoscope 1986;96:1073-1082. 